\title{
A New Natural Antioxidant Mixture Protects against Oxidative and DNA Damage in Endothelial Cell Exposed to Low-Dose Irradiation
}

\author{
T. Cervelli, ${ }^{1}$ D. Panetta, ${ }^{1}$ T. Navarra, ${ }^{1}$ S. Gadhiri, ${ }^{1}$ P. Salvadori, ${ }^{1}$ A. Galli, ${ }^{1}$ D. Caramella, ${ }^{2}$ \\ G. Basta, ${ }^{1}$ E. Picano, ${ }^{1}$ and S. Del Turco ${ }^{1}$ \\ ${ }^{1}$ Institute of Clinical Physiology, Council of National Research (CNR), Via Moruzzi, 1, 56124 Pisa, Italy \\ ${ }^{2}$ Radiologia Diagnostica e Interventistica, Università di Pisa, Pisa, Italy
}

Correspondence should be addressed to S. Del Turco; serena@ifc.cnr.it

Received 6 March 2017; Revised 17 May 2017; Accepted 3 July 2017; Published 9 August 2017

Academic Editor: Walid Rachidi

Copyright (c) 2017 T. Cervelli et al. This is an open access article distributed under the Creative Commons Attribution License, which permits unrestricted use, distribution, and reproduction in any medium, provided the original work is properly cited.

\begin{abstract}
Exposure to ionizing radiation during diagnostic procedures increases systemic oxidative stress and predisposes to higher risk of cancer and cardiovascular disease development. Many studies indicated that antioxidants protect against radiation-induced damage and have high efficacy and lack of toxicity in preventing radiation exposure damages. The purpose of this study was to investigate the in vitro protective effect of a new antioxidant mixture, named RiduROS, on oxidative stress generation and DNA double-strand breaks (DSBs) induced by low doses of X-rays in endothelial cells. Human umbilical vein endothelial cells (HUVEC) were treated with RiduROS mixture $24 \mathrm{~h}$ before a single exposure to X-rays at an absorbed dose of $0.25 \mathrm{~Gy}$. The production of reactive oxygen species (ROS) was evaluated by fluorescent dye staining and nitric oxide (NO) by the Griess reaction, and DSBs were evaluated as number of $\gamma$-H2AX foci. We demonstrated that antioxidant mixture reduced oxidative stress induced by low dose of X-ray irradiation and that RiduROS pretreatment is more effective in protecting against radiationinduced oxidative stress than single antioxidants. Moreover, RiduROS mixture is able to reduce $\gamma$-H2AX foci formation after low-dose X-ray exposure. The texted mixture of antioxidants significantly reduced oxidative stress and $\gamma$-H2AX foci formation in endothelial cells exposed to low-dose irradiation. These results suggest that RiduROS could have a role as an effective radioprotectant against low-dose damaging effects.
\end{abstract}

\section{Introduction}

The employment of medical imaging diagnostic procedures delivering relatively low doses of ionizing radiation (IR) has never stop to grow since the last years $[1,2]$. Despite many clinical advantages, exposure IR, even at low-doses, may cause damage at biological systems and predispose individuals at an increasing risk of developing cancer and cardiovascular diseases (CVD) [3-5]. Low doses of IR induce oxidative stress [6-8]. The excessive accumulation of ROS may provoke structural modifications to biological systems inducing cellular damage $[9,10]$. DNA double-strand breaks (DSBs) are the most serious consequence of free radicals after radiation exposure [11] and, if inefficiently repaired, can lead to carcinogenesis and predispose to vascular aging processes $[12,13]$.

Endothelium seems to play an important role in the cardiovascular response to ionizing radiation. Alterations of endothelial function induced by low-dose irradiation increases the risk of CVD [14]. We have previously showed that low doses of X-ray irradiation can induce oxidative stress and DSBs in human endothelial cells predisposing to accelerate vascular inflammation, from which the atherosclerotic process can arise [15].

Recently, there has been a growing interest in research into the protective role of antioxidant agents against radiationinduced oxidative stress [16]. ROS-mediated harmful effects may be promptly quenched not only by endogenous defense 
mechanisms but also by taking supplements of antioxidants that are able to quench oxidative stress caused by ionizing radiation, therefore reducing the potential risks for human health [16]. In vitro and animal studies [17-20] have demonstrated the efficacy of multiple antioxidants in the protection of tissues from damage induced by ionizing radiation.

Since increased ROS generation occurs in different cellular compartments inducing cell damage at multiple levels, the use of combined antioxidants would represent a more effective strategy in protecting against radiation damage than single antioxidant [21].

Focusing on this, a new mixture of antioxidants, RiduROS, has been developed selecting nutrients or molecules such as resveratrol, Extramel ${ }^{\circledR}$, seleno-L-methionine, Curcuma longa, reduced L-glutathione, and vitamin $\mathrm{C}$ that are well-known for their antioxidant capacity. Curcumin, a phenolic compound from the rhizomes of Curcuma longa, is a powerful scavenger of superoxide anion [22] and shows protective effects against radiation-induced damage [23], reducing oxidative stress, inflammatory response [24], and DNA damage [25]. Resveratrol, a natural polyphenol compound [26] with reported antioxidant and anticarcinogenic effects, has received particular interest as a radioprotector with the potential for widespread application $[27,28]$. Lselenium methionine is an essential component of several antioxidant enzymes that does not act as a free radical scavenger, but acts indirectly providing protection against oxidative stress. Reduced L-glutathione [29] and vitamin C [30] have been observed to mitigate the DNA damage induced by ionizing radiation by scavenging reactive oxygen species. Extramel is a melon juice concentrate rich in superoxide dismutase (SOD), with potential beneficial effects on the development of atherosclerosis and liver steatosis, characterized by an increased oxidative stress and chronic inflammation [31]. SOD is an endogenous antioxidant enzyme that can confer radioresistance [32] or radiosensitivity [33], whether over- or downexpressed, respectively, and it has been successfully used as a treatment in chronic damage induced by radiotherapy in humans $[34,35]$.

The objectives of this study were to evaluate the effect of RiduROS mixture on oxidative stress induced by low-dose Xray in human endothelial cells and to show its effect on DSBs, one form of DNA damage induced by oxidative stress.

\section{Material and Methods}

2.1. RiduROS Composition. RiduROS is composed by a mixture of antioxidants in different percentages (weigh percent, \%) as follows: resveratrol (45\%), Extramel (2.15\%), seleno-L-methionine (2\%), Curcuma longa (42\%), reduced L-glutathione (6\%), and vitamin C (2.4\%) (supplied by BRG Farmaceutica, Grosseto, Italy).

RiduROS was soluble in dimethyl sulfoxide (DMSO), an organic solvent, at a concentration of $20 \mathrm{mg} / \mathrm{mL}$. Further dilutions of the mixture were performed in culture medium to reach the specified final concentrations for the experiments. The same batch of RiduROS was tested in all experiments, as provided by BRG. Contribution of each compound to antioxidant activity was tested at one concentration only-the equivalent of its concentration in $1 \mu \mathrm{g} / \mathrm{mL}$ RiduROS.

2.2. X-Ray Irradiation Setup and Calibration. The experimental setup for X-ray irradiation consists of a system aligned on a vertical axis, with variable source-to-object distance in the range of $90-375 \mathrm{~mm}$. Polystyrene Petri dishes or microwell plates (Corning/Costar Inc., Cambridge, USA) are placed above a $1 \mathrm{~cm}$-thick block of polymethyl methacrylate (PMMA) [15]. For operator safety, the whole system is enclosed in a shielded cabinet $(<1 \mu \mathrm{Sv} / \mathrm{h}$ at each accessible point during operation). The $\mathrm{X}$-ray source (Apogee, Oxford Instruments, USA) is a packaged X-ray tube with fixed tungsten anode and $125 \mu \mathrm{m}$-thick beryllium window, operating in continuous mode. An additional $1 \mathrm{~mm}$-thick aluminium filter was placed in front of the X-ray exit window. The maximum accelerating voltage and filament current are $50 \mathrm{kV}$ and $1 \mathrm{~mA}$, respectively (50 W max. continuous power).

The X-ray tube is operated by a general purpose personal computer through a dedicated controller with RS232 interface (ADIO232, RFS Systems, Straubenhardt, Germany). The average irradiation time for a total dose of $0.25 \mathrm{~Gy}$ was $164 \mathrm{~s}$, corresponding to a dose rate of $91 \mathrm{mGy} / \mathrm{min}$.

For all the experiments, the irradiation parameters were $50 \mathrm{kV}, 0.7 \mathrm{~mA}$, source-to-object distance $=211 \mathrm{~mm}$. Thermoluminescent dosimeters (TLD-100, Harshaw) at the same position of the specimen were used before experiments to calibrate the system in term of absorbed dose.

\subsection{Endothelial Cell Culture and Experimental Design.} Human umbilical vein endothelial cells (HUVEC) were harvested and isolated by enzymatic digestion in the presence of type II collagenase $(0.1 \%)$ as described before [36]. Isolated cells were maintained in Medium 199 (Life Sciences, Grand Island, NY, USA), containing fetal bovine serum (10\%), antibiotics, and growth factors (heparin, $50 \mathrm{U} / \mathrm{mL}$, and endothelial cell growth factor, $10 \mathrm{mg} / \mathrm{mL}$ ) (all from Sigma-Aldrich, St. Louis, MO, USA). Human cells were obtained from discarded umbilical cords and treated anonymously; as such, approval from the University Ethics Review Board was not necessary. HUVEC were used at passage 2 after primary culture. Cell monolayers were pretreated with RiduROS $(0.1,1$, and $10 \mu \mathrm{g} / \mathrm{mL}$ ) or a single compound for $24 \mathrm{~h}$ before exposure to a single final dose of $0.25 \mathrm{~Gy} \mathrm{X}$-ray radiations with a dose corresponding to maximum oxidative stress generation compared with the control, as previously demonstrated [15]. Incubation with only DMSO $(0.0075 \%$, the final percent to reach the concentration of RiduROS $1 \mu \mathrm{g} / \mathrm{mL}$ ) was run in parallel, and no inhibition of oxidative stress was observed with DMSO after irradiation. Control cells were treated exactly as irradiated samples, except for irradiation and/or drug treatments.

2.4. Cell Viability Assay. HUVEC, seeded in 96-well microplates, were treated with RiduROS $(0.1,1$, and $10 \mu \mathrm{g} / \mathrm{mL}$ ) and the effects on cell viability was monitored at 24 and $48 \mathrm{~h}$ after treatment. The viability of HUVEC was assayed 
by colorimetric assay using WST-1 (Biovision, San Francisco, USA) which was based on cleavage in viable cells of the water-soluble tetrazolium salt WST-1 [2-(4-iodophenyl)-3(4-nitrophenyl)-5-(2,4-disul-fonyl)-2H-tetrazolium, monosodium salt] to a formazan dye by mitochondrial dehydrogenase. Briefly, cells cultured in 96-well plates were treated with different concentrations of RiduROS or a single antioxidant component for $24-48 \mathrm{~h}$. Then, $10 \mu \mathrm{L}$ WST-1 reagent was added to each well and HUVEC were incubated for $4 \mathrm{~h}$ at $37^{\circ} \mathrm{C}$. The formazan dye produced was quantified by measuring the absorbance of the dye solution at $450 \mathrm{~nm}$ with a microplate reader.

2.5. Detection of Intracellular ROS Generation. Generation of ROS in HUVEC was measured with $25 \mu \mathrm{mol} / \mathrm{L}$ of the fluorescent dye 6-carboxy-2 $2^{\prime}, 7^{\prime}$-dichlorodihydrofluorescein diacetate bis(acetoxymethyl)-ester (C-DCDHF-DA) (Molecular Probes Inc., Eugene, OR, USA), which is a cell-permeable nonfluorescent probe that, after uptake, is cleaved by intracellular esterases to carboxy dichlorofluorescein. In this status, C-DCDHF-DA is trapped within the cells and oxidized by ROS to highly fluorescent product. The fluorescence intensity is proportional to the level of intracellular oxidative stress [37]. Specifically, HUVEC, treated as described above, were washed with phenol red-free Hanks'-buffered saline (Sigma), treated with C-DCDHF$\mathrm{DA}$ for $30 \mathrm{~min}$ at $37^{\circ} \mathrm{C}$, and then irradiated. Forty-five minutes after irradiation, ROS generation was evaluated; cells were washed and scraped off into $1 \mathrm{~mL}$ of distilled water, sonicated, and centrifuged. The fluorescence of supernatants was measured with a spectrofluorometer at $485 \mathrm{~nm}$ excitation and $525 \mathrm{~nm}$ emission.

\subsection{Determination of Nitrite/Nitrate Production. HUVEC} were treated as described above, supernatants were collected, and total levels of nitrate plus nitrite, the final products of nitric oxide, were measured with the Griess assay kit (Cayman Chemical Co., Ann Arbor, MI, USA). Concentration of $\mathrm{NO}_{2}{ }^{-} / \mathrm{NO}_{3}{ }^{-}$was corrected for the cell number and expressed as $\mu \mathrm{mol} / \mathrm{L} / 10^{5}$ cells [38].

2.7. Immunofluorescence Microscopy and Semiquantification of $\gamma \mathrm{H} 2 \mathrm{AX}$ Foci. The number of phosphorylated $\gamma$-H2AX foci in cell nuclei is an efficient marker for scoring radiationinduced DSBs [36, 39]. HUVEC were seeded on glass cover slips at $80 \%$ of confluence the day before treatment in order to have a monolayer the day of irradiation. The cells were fixed with $2 \%$ paraformaldehyde $2 \mathrm{~h}$ after irradiation and treated as previously described [36]. The primary antibody against $\gamma$-H2AX (anti-phospho-Histone H2AX (Ser139), clone JBW301, Millipore) was diluted at 1:200 in PBS containing BSA/glycine. The secondary antibody tagged to a fluorescent group (Alexa Fluor 594 goat $\alpha$-mouse IgG, Thermo Fisher Scientific) was applied diluted at 1:500 in PBS with BSA/glycine. Cover slips were put on object glasses covered with DAPI/Vectashield and sealed.

Analysis of foci formation was performed using a ZEISS Axioskop40 fluorescence microscope equipped with a $\times 100$ magnification objective. In each sample, the number of foci

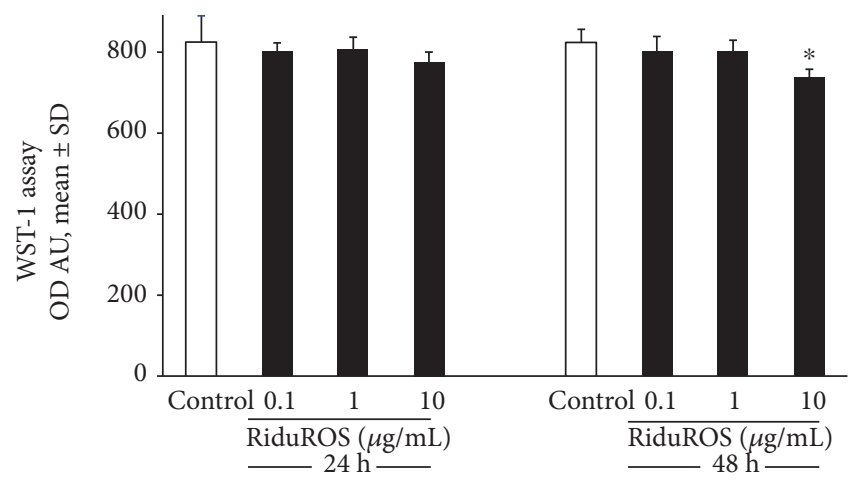

FIgUre 1: Effect of RiduROS on endothelial cell viability. Cell viability was assessed by WST-1 24-48 h after treatment with RiduROS $(0.1,1$, and $10 \mu \mathrm{g} / \mathrm{mL})$. Data are expressed as mean $\pm \mathrm{SD}$ of optical density (OD) arbitrary units at $450 \mathrm{~nm}$ and are representatives of three independent experiments. ${ }^{*} P<0.05$ versus control cells.

was counted in 100 cells. The number of foci/cell was determined by the ratio between total number of foci and total enumerated cells.

2.8. Statistical Analysis. Two-group comparisons were performed by unpaired Student's $t$-test. Multiple comparisons were performed by one-way analysis of variance (ANOVA) followed by a multiple comparison test (Bonferroni test). The percent of inhibition was normalized for control cells. Values of $P<0.05$ were considered statistically significant.

\section{Results}

The main objective of this study was to assess RiduROS ability in protecting endothelial cells from oxidative and DNA damage induced by exposure to low dose of X-rays. It was observed that the treatment with RiduROS mixture $(0.1,1$, and $10 \mu \mathrm{g} / \mathrm{mL}$ ) did not affect cell viability up to $1 \mu \mathrm{g} / \mathrm{mL}$ at 24-48 hours after treatment, as shown in Figure 1. At $10 \mu \mathrm{g} / \mathrm{mL}$, we observed a weak reduction in cell viability after $24 \mathrm{~h}$ of treatment (10\%) that increases significantly after $48 \mathrm{~h}$ (16\%). This decrease, probably, is due to coadministration and high concentrations of antioxidants that augment the clearance of physiologically levels of free radicals, which are essential to regulate intracellular signaling processes and to guarantee the structural integrity of cellular components. The application of antioxidant mixture 24 hours before irradiation proved to be the most effective incubation time in reducing oxidative stress compared to $1 \mathrm{~h}$ (97\% versus $18 \%$, data not shown), compatible with appropriated delivery and distribution of antioxidants inside cells. So, all experiments were performed pretreating HUVEC with RiduROS for $24 \mathrm{~h}$. Oxidative stress was evaluated 45 minutes after irradiation with $0.25 \mathrm{~Gy} \mathrm{X}$-rays, corresponding to the time of maximum increase in the ROS generation [15]. Results showed that the pretreatment with the antioxidant mixture blunted ROS generation in a concentration-dependent manner by $65 \% \pm 5.6 \%$ and $98 \% \pm 2 \%$, at 0.1 and $1 \mu \mathrm{g} / \mathrm{mL}$, respectively, compared with cells irradiated without pretreatment (Figure 2). The contribution of each substance to 


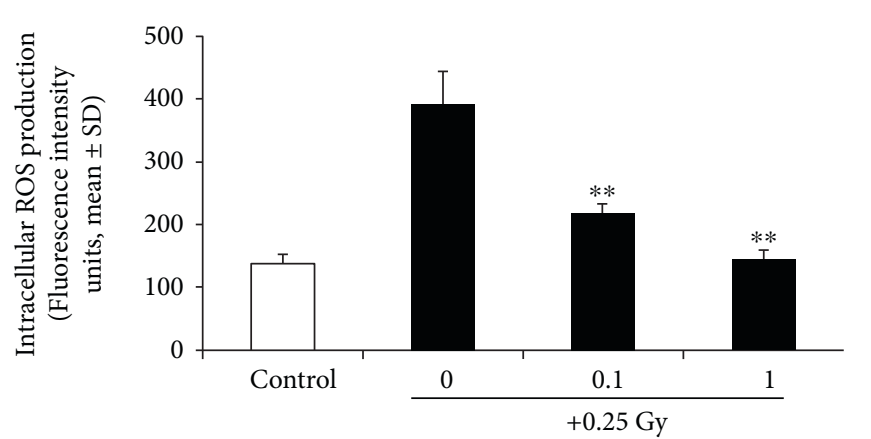

RiduROS $(\mu \mathrm{g} / \mathrm{mL})$

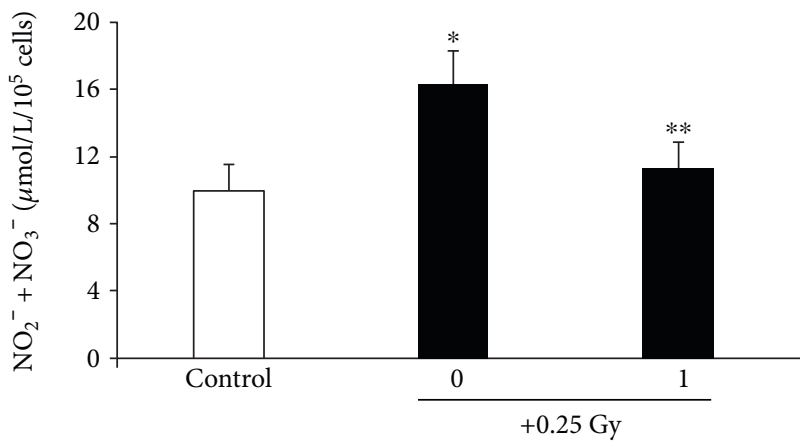

$\operatorname{RiduROS}(\mu \mathrm{g} / \mathrm{mL})$

(a)

(b)

FIGURE 2: RiduROS inhibited ROS generation and restore NO levels after low-dose irradiation. (a) HUVEC were pretreated with RiduROS $(0.1-1 \mu \mathrm{g} / \mathrm{mL})$, then exposed to $0.25 \mathrm{~Gy}$ of radiation. After $45 \mathrm{~min}$ of incubation, monolayers were harvested and lysed for quantitative determination of ROS. All values are expressed as mean \pm SD of arbitrary fluorescence units of three independent experiments. ${ }^{* *} P<0.001$ versus $0.25 \mathrm{~Gy}$ alone. (b) Supernatants were collected $24 \mathrm{~h}$ after irradiation and total levels of nitrate/nitrite were measured. Data are mean $\pm \mathrm{SD}$ and representatives of three independent experiments and expressed as $\mu \mathrm{mol} / \mathrm{L} / 10^{5}$ cells. ${ }^{*} P<0.05$ versus control cells; ${ }^{* *} P<0.05$ versus 0.25 Gy alone.

TABLE 1: Effect of single antioxidant and RiduROS on ROS generation detected by dichlorofluorescein assay.

\begin{tabular}{lc}
\hline Antioxidant component of RiduROS & $\begin{array}{c}\text { \% of inhibition of } \\
\text { oxidative stress }\end{array}$ \\
\hline Resveratrol $(1 \mu \mathrm{M})$ & $57 \% \pm 8$ \\
Extramel melon pulp $(0.00025 \mathrm{UI})$ & $48 \% \pm 5$ \\
Seleno-L-methionine $(0.5 \mathrm{nM})$ & $51 \% \pm 6$ \\
Curcuma longa $(225 \mathrm{nM})$ & $79 \% \pm 3$ \\
Reduced L-glutathione $(0.25 \mu \mathrm{M})$ & $29 \% \pm 5$ \\
Vitamin C $(200 \mu \mathrm{mol} / \mathrm{L})$ & $39 \% \pm 6$ \\
RiduROS $(1 \mu \mathrm{g} / \mathrm{mL})$ & $98 \% \pm 2$ \\
\hline
\end{tabular}

antioxidant activity, at concentrations equivalent to that in the RiduROS $1 \mu \mathrm{g} / \mathrm{mL}$, was also tested. As evident in Table 1, the resveratrol and Curcuma longa were highly protective against oxidative stress induced by low-dose irradiation with an inhibition percent of $57 \%$ and $79 \%$, respectively. Extramel and L-seleno-L-methionine inhibit ROS generation by $48 \%$ and $41 \%$, respectively. Conversely, vitamin $\mathrm{C}$ and reduced glutathione showed a lower antioxidant activity, decreasing oxidative stress by $29 \%$ and $39 \%$, respectively (Table 1 ).

Once demonstrated that the RiduROS mixture suppresses oxidative stress, highlighting the advantage of using multiple antioxidants, we have also evaluated its effect both on NO levels and on number of $\gamma$-H2AX-foci induced by 0.25 Gy X-rays.

Low dose of X-rays reduce NO levels by $36 \%$, measured as concentration of nitrite and nitrate, indicating an impairment of endothelial function, while RiduROS tends to restore NO within its physiological range (Figure 2(b)).

As shown in Figure 3, low-dose irradiation increased DSB-induced $\gamma$-H2AX foci compared with control cells and $24 \mathrm{~h}$ of RiduROS pretreatment reduces of $41 \%$ the $\gamma-\mathrm{H} 2 \mathrm{AX}$

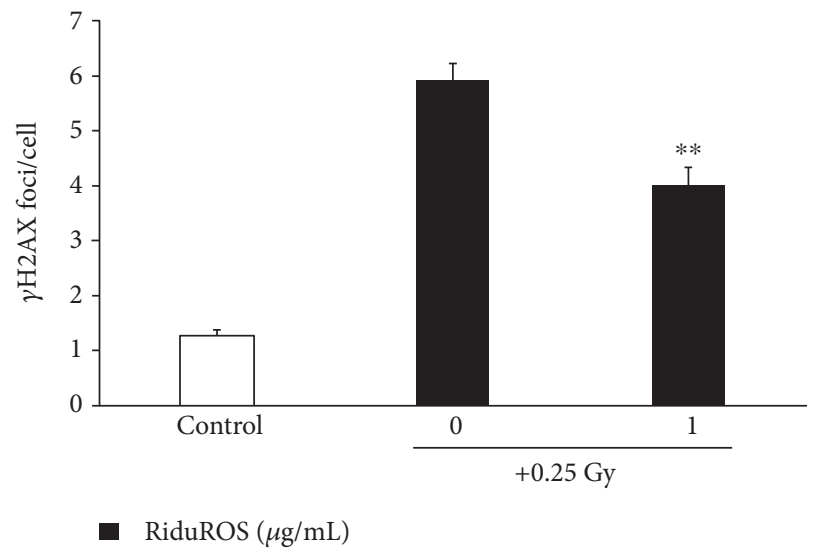

FIGURE 3: RiduROS reduced the number of $\gamma$-H2AX foci/cell after low-dose irradiation. HUVEC were pretreated with RiduROS $(1 \mu \mathrm{g} / \mathrm{mL})$, then exposed to $0.25 \mathrm{~Gy}$ of radiation and fixed after $2 \mathrm{~h}$. All values are expressed as mean $\pm \mathrm{SD}$ of foci/cell of three independent experiments. ${ }^{* *} P<0.05$ versus 0.25 Gy alone.

foci number, therefore providing a beneficial effect on DNA damage.

\section{Discussion}

The increasing exposure to radiation associated to diagnostic procedures requires insight into human health risks, especially in terms of carcinogenic and cardiovascular risks $[40,41]$. Low doses of ionizing radiation used in diagnostic imaging procedures can produce acute and long-term side effects by free radicals that affect DNA and biological molecules ultimately resulting in molecular and biochemical alterations [42]. DSBs are considered the most significant DNA lesions induced by ionizing radiation [43]. We have previously demonstrated that low doses of X-rays are capable of inducing free radical generation and DSBs in human endothelial cells [15]. 
The present study was designed to investigate the protective effects of a new mixture of antioxidants on oxidative and DNA damage-induced by X-ray irradiation at low dose.

At present, the development of novel and effective agents to combat radiation damages is of considerable interest particularly in radio diagnostics. To quench the effect of free radicals, antioxidant treatment may be useful in reducing radiation-related adverse effects. Ionizing radiation produces many types of free radicals that interact with various cellular targets. As antioxidants have multiple distribution/localization into the cell and different binding activities for free radicals, the use of a mixture of multiple antioxidants may result more effective in decreasing the oxidative stress than individual agents themselves.

Both in vitro and in vivo studies on animal models have demonstrated the beneficial effect of antioxidants on damage induced by ionizing radiation. In particular, the combined use of more than one antioxidant, such as vitamin $\mathrm{E}$ and selenium [17] or vitamins $\mathrm{C}$ and $\mathrm{E}$ [44], turned out to be more effective in reducing radiation-induced mutations and chromosomal damage than individual agents. These results support animal data, showing that a mixture of multiple antioxidants (i.e., sodium ascorbate, $\mathrm{N}$-acetyl cysteine, $\alpha$-lipoic acid, and coenzyme Q10 vitamins) protected mice against oxidative stress [45]. Studies in multiple antioxidant research indicate a reduction of the chromosomal and oxidative damage in subjects undergoing radiotherapy $[16,46]$ and in children chronically exposed to low doses of radiation in the Chernobyl area [47]. N-acetylcysteine, a naturally occurring compound found in several vegetables and one of the least toxic thiol reducing agents, may be an effective mean of preventing DNA damage induced by ionizing radiation exposure as during cardiac catheterization procedures [48]. A formulation of antioxidants and glutathione-elevating enzymes reduces the amount of X-ray-induced $\gamma$-H2AX at a typical dose for a computed tomography scan and other radiographic or scintigraphic studies [49].

However, at present, the efficacy of combined antioxidant strategy to reduce the side effects of low doses of X-rays, as administered during diagnostic procedures, has not yet been tested in humans.

Our results have demonstrated that all antioxidants of RiduROS are able to reduce oxidative stress induced by low-dose irradiation and complete or nearly complete reduction was achieved with RiduROS mixture applied before the radiation exposure.

Moreover, ROS reduction was accompanied both by increase of NO concentration, by restoration of endothelial function, and by reduction of $\gamma-\mathrm{H} 2 \mathrm{AX}$ foci supporting the efficacy of RiduROS treatment in protecting DNA from DSBs.

Since individuals are exposed to very low doses of ionizing radiation for early diagnosis of diseases, the development of useful and nontoxic agents to combat radiation damage and protect biological systems is of paramount importance. The results of our study suggest that the RiduROS could have a role as an effective radioprotector against low-dose damaging effects and considered in future clinical trials to evaluate the relevance for patients.

\section{Disclosure}

The authors alone are responsible for the content and writing of the paper.

\section{Conflicts of Interest}

The authors declare that they have no conflicts of interest.

\section{Acknowledgments}

This work was funded by an unrestricted grant from BRG Farmaceutica s.r.l., Grosseto, to the CNR Institute of Clinical Physiology, Pisa.

\section{References}

[1] US Food and Drug Administration, Initiative to Reduce Unnecessary Radiation Exposure from Medical Imaging, White Paper, Center for Devices and Radiological Health U.S. Food and Drug Administration, 2010.

[2] A. S. Minhas and D. P. Frush, "Compendium of resources for radiation safety in medical imaging using ionizing radiation," Journal of the American College of Radiology, vol. 10, no. 5, pp. 354-360.e2, 2013.

[3] R. Fazel, H. M. Krumholz, Y. Wang et al., "Exposure to lowdose ionizing radiation from medical imaging procedures," The New England Journal of Medicine, vol. 361, no. 9, pp. 849-857, 2009.

[4] J. E. Baker, J. E. Moulder, and J. W. Hopewell, "Radiation as a risk factor for cardiovascular disease," Antioxidants \& Redox Signaling, vol. 15, no. 7, pp. 1945-1956, 2011.

[5] F. A. Stewart, "Mechanisms and dose-response relationships for radiation-induced cardiovascular disease," Annals of the ICRP, vol. 41, no. 3-4, pp. 72-79, 2012.

[6] D. Schaue, B. Marples, and K. R. Trott, "The effects of low-dose $\mathrm{X}$-irradiation on the oxidative burst in stimulated macrophages," International Journal of Radiation Biology, vol. 78, no. 7, pp. 567-576, 2002.

[7] S. V. Kostyuk, A. V. Ermakov, A. Y. Alekseeva et al., "Role of extracellular DNA oxidative modification in radiation induced bystander effects in human endotheliocytes," Mutation Research, vol. 729, no. 1-2, pp. 52-60, 2012.

[8] A. V. Ermakov, M. S. Konkova, S. V. Kostyuk, N. A. Egolina, L. V. Efremova, and N. N. Veiko, "Oxidative stress as a significant factor for development of an adaptive response in irradiated and nonirradiated human lymphocytes after inducing the bystander effect by low-dose X-radiation," Mutation Research, vol. 669, no. 1-2, pp. 155-161, 2009.

[9] D. P. Jones, "Radical-free biology of oxidative stress," American Journal of Physiology. Cell Physiology, vol. 295, no. 4, pp. C849-C868, 2008.

[10] J. Z. Guan, W. P. Guan, T. Maeda, and N. Makino, "Changes in telomere length distribution in low-dose X-ray-irradiated human umbilical vein endothelial cells," Molecular and Cellular Biochemistry, vol. 396, 2014.

[11] M. Lobrich, N. Rief, M. Kuhne et al., "In vivo formation and repair of DNA double-strand breaks after computed tomography examinations," Proceedings of the National Academy of Sciences of the United States of America, vol. 102, no. 25, pp. 8984-8989, 2005. 
[12] P. A. Jeggo and M. Lobrich, "DNA double-strand breaks: their cellular and clinical impact?," Oncogene, vol. 26, no. 56, pp. 7717-7719, 2007.

[13] A. Borghini, T. Cervelli, A. Galli, and M. G. Andreassi, "DNA modifications in atherosclerosis: from the past to the future," Atherosclerosis, vol. 230, no. 2, pp. 202-209, 2013.

[14] B. Baselet, C. Rombouts, A. M. Benotmane, S. Baatout, and A. Aerts, "Cardiovascular diseases related to ionizing radiation: the risk of low-dose exposure (review)," International Journal of Molecular Medicine, vol. 38, no. 6, pp. 16231641, 2016.

[15] T. Cervelli, D. Panetta, T. Navarra et al., "Effects of single and fractionated low-dose irradiation on vascular endothelial cells," Atherosclerosis, vol. 235, no. 2, pp. 510-518, 2014.

[16] M. T. Giardi, E. Touloupakis, D. Bertolotto, and G. Mascetti, "Preventive or potential therapeutic value of nutraceuticals against ionizing radiation-induced oxidative stress in exposed subjects and frequent fliers," International Journal of Molecular Sciences, vol. 14, no. 8, pp. 17168-17192, 2013.

[17] C. Borek, A. Ong, H. Mason, L. Donahue, and J. E. Biaglow, "Selenium and vitamin E inhibit radiogenic and chemically induced transformation in vitro via different mechanisms," Proceedings of the National Academy of Sciences of the United States of America, vol. 83, no. 5, pp. 1490-1494, 1986.

[18] R. D. Blumenthal, W. Lew, A. Reising et al., "Anti-oxidant vitamins reduce normal tissue toxicity induced by radioimmunotherapy," International Journal of Cancer, vol. 86, no. 2, pp. 276-280, 2000.

[19] A. R. Kennedy and N. I. Krinsky, "Effects of retinoids, betacarotene, and canthaxanthin on UV- and X-ray-induced transformation of $\mathrm{C} 3 \mathrm{H} 10 \mathrm{~T} 1 / 2$ cells in vitro," Nutrition and Cancer, vol. 22, no. 3, pp. 219-232, 1994.

[20] X. S. Wan, J. H. Ware, Z. Zhou, J. J. Donahue, J. Guan, and A. R. Kennedy, "Protection against radiation-induced oxidative stress in cultured human epithelial cells by treatment with antioxidant agents," International Journal of Radiation Oncology, Biology, Physics, vol. 64, no. 5, pp. 1475-1481, 2006.

[21] K. N. Prasad, "Rationale for using multiple antioxidants in protecting humans against low doses of ionizing radiation," The British Journal of Radiology, vol. 78, no. 930, pp. 485492, 2005.

[22] V. Calabrese, T. E. Bates, C. Mancuso et al., "Curcumin and the cellular stress response in free radical-related diseases," Molecular Nutrition \& Food Research, vol. 52, no. 9, pp. 1062-1073, 2008.

[23] M. Akpolat, M. Kanter, and M. C. Uzal, "Protective effects of curcumin against gamma radiation-induced ileal mucosal damage," Archives of Toxicology, vol. 83, no. 6, pp. 609-617, 2009.

[24] G. C. Jagetia, "Radioprotection and radiosensitization by curcumin," Advances in Experimental Medicine and Biology, vol. 595, pp. 301-320, 2007.

[25] H. Ogiwara, A. Ui, B. Shiotani, L. Zou, A. Yasui, and T. Kohno, "Curcumin suppresses multiple DNA damage response pathways and has potency as a sensitizer to PARP inhibitor," Carcinogenesis, vol. 34, no. 11, pp. 2486-2497, 2013.

[26] R. Nakata, S. Takahashi, and H. Inoue, "Recent advances in the study on resveratrol," Biological \& Pharmaceutical Bulletin, vol. 35, no. 3, pp. 273-279, 2012.
[27] R. E. Carsten, A. M. Bachand, S. M. Bailey, and R. L. Ullrich, "Resveratrol reduces radiation-induced chromosome aberration frequencies in mouse bone marrow cells," Radiation Research, vol. 169, no. 6, pp. 633-638, 2008.

[28] N. G. Denissova, C. M. Nasello, P. L. Yeung, J. A. Tischfield, and M. A. Brenneman, "Resveratrol protects mouse embryonic stem cells from ionizing radiation by accelerating recovery from DNA strand breakage," Carcinogenesis, vol. 33, no. 1, pp. 149$155,2012$.

[29] A. Chatterjee, "Reduced glutathione: a radioprotector or a modulator of DNA-repair activity?," Nutrients, vol. 5, no. 2, pp. 525-542, 2013.

[30] M. Kanter and M. Akpolat, "Vitamin C protects against ionizing radiation damage to goblet cells of the ileum in rats," Acta Histochemica, vol. 110, no. 6, pp. 481-490, 2008.

[31] K. Decorde, E. Ventura, D. Lacan, J. Ramos, J. P. Cristol, and J. M. Rouanet, "An SOD rich melon extract Extramel prevents aortic lipids and liver steatosis in diet-induced model of atherosclerosis," Nutrition, Metabolism, and Cardiovascular Diseases, vol. 20, no. 5, pp. 301-307, 2010.

[32] C. O. Brown, K. Salem, B. A. Wagner et al., "Interleukin-6 counteracts therapy-induced cellular oxidative stress in multiple myeloma by up-regulating manganese superoxide dismutase," The Biochemical Journal, vol. 444, no. 3, pp. 515-527, 2012.

[33] Y. Xu, F. Fang, D. K. S. Clair et al., "Suppression of RelBmediated manganese superoxide dismutase expression reveals a primary mechanism for radiosensitization effect of 1alpha,25-dihydroxyvitamin $\mathrm{D}(3)$ in prostate cancer cells," Molecular Cancer Therapeutics, vol. 6, no. 7, pp. 2048-2056, 2007.

[34] S. Delanian, M. Martin, A. Bravard, C. Luccioni, and J. L. Lefaix, " $\mathrm{Cu} / \mathrm{Zn}$ superoxide dismutase modulates phenotypic changes in cultured fibroblasts from human skin with chronic radiotherapy damage," Radiotherapy and Oncology, vol. 58, no. 3, pp. 325-331, 2001.

[35] B. Gauter-Fleckenstein, K. Fleckenstein, K. Owzar, C. Jiang, I. Batinic-Haberle, and Z. Vujaskovic, "Comparison of two Mn porphyrin-based mimics of superoxide dismutase in pulmonary radioprotection," Free Radical Biology \& Medicine, vol. 44, no. 6, pp. 982-989, 2008.

[36] S. Del Turco, G. Ciofani, V. Cappello et al., "Cytocompatibility evaluation of glycol-chitosan coated boron nitride nanotubes in human endothelial cells," Colloids and Surfaces B, Biointerfaces, vol. 111, pp. 142-149, 2013.

[37] G. Basta, G. Lazzerini, S. Del Turco, G. M. Ratto, A. M. Schmidt, and R. De Caterina, "At least 2 distinct pathways generating reactive oxygen species mediate vascular cell adhesion molecule-1 induction by advanced glycation end products," Arteriosclerosis, Thrombosis, and Vascular Biology, vol. 25, no. 7, pp. 1401-1407, 2005.

[38] G. Lazzerini, S. Del Turco, G. Basta, A. O’Loghlen, A. Zampolli, and R. De Caterina, "Prominent role of NF-kappaB in the induction of endothelial activation by endogenous nitric oxide inhibition," Nitric Oxide, vol. 21, no. 3-4, pp. 184-191, 2009.

[39] L. G. Mariotti, G. Pirovano, K. I. Savage et al., "Use of the gamma-H2AX assay to investigate DNA repair dynamics following multiple radiation exposures," PLoS One, vol. 8, no. 11, article e79541, 2013.

[40] P. K. Nguyen and J. C. Wu, "Radiation exposure from imaging tests: is there an increased cancer risk?," Expert Review of Cardiovascular Therapy, vol. 9, no. 2, pp. 177-183, 2011. 
[41] E. Picano, E. Vano, M. M. Rehani et al., "The appropriate and justified use of medical radiation in cardiovascular imaging: a position document of the ESC associations of cardiovascular imaging, percutaneous cardiovascular interventions and electrophysiology," European Heart Journal, vol. 35, no. 10, pp. 665-672, 2014.

[42] T. Hampton, "Researchers examine long-term risks of exposure to medical radiation," The Journal of the American Medical Association, vol. 296, no. 6, pp. 638-640, 2006.

[43] M. Brand, M. Sommer, S. Achenbach et al., "X-ray induced DNA double-strand breaks in coronary CT angiography: comparison of sequential, low-pitch helical and high-pitch helical data acquisition," European Journal of Radiology, vol. 81, no. 3, pp. e357-e362, 2012.

[44] U. Mutlu-Turkoglu, Y. Erbil, S. Oztezcan, V. Olgaç, G. Token, and M. Uysal, "The effect of selenium and/or vitamin E treatments on radiation-induced intestinal injury in rats," Life Sciences, vol. 66, no. 20, pp. 1905-1913, 2000.

[45] S. L. Brown, A. Kolozsvary, J. Liu, K. A. Jenrow, S. Ryu, and J. H. Kim, "Antioxidant diet supplementation starting 24 hours after exposure reduces radiation lethality," Radiation Research, vol. 173, no. 4, pp. 462-468, 2010.

[46] A. Yasueda, H. Urushima, and T. Ito, "Efficacy and interaction of antioxidant supplements as adjuvant therapy in cancer treatment: a systematic review," Integrative Cancer Therapies, vol. 15, no. 1, pp. 17-39, 2016.

[47] A. Ben-Amotz, S. Yatziv, M. Sela et al., "Effect of natural betacarotene supplementation in children exposed to radiation from the Chernobyl accident," Radiation and Environmental Biophysics, vol. 37, no. 3, pp. 187-193, 1998.

[48] M. G. Andreassi, A. Cioppa, S. Manfredi, M. G. Neri, I. Foffa, and E. Picano, "N-acetyl cysteine reduces chromosomal DNA damage in circulating lymphocytes during cardiac catheterization procedures: a pilot study," International Journal of Cardiology, vol. 161, no. 2, pp. 93-96, 2012.

[49] M. A. Kuefner, M. Brand, J. Ehrlich, L. Braga, M. Uder, and R. C. Semelka, "Effect of antioxidants on X-ray-induced gamma-H2AX foci in human blood lymphocytes: preliminary observations," Radiology, vol. 264, no. 1, pp. 59-67, 2012. 


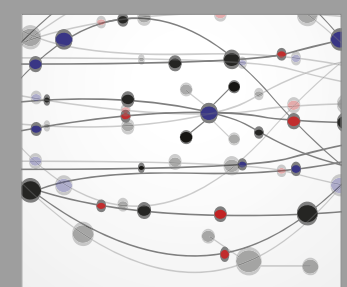

The Scientific World Journal
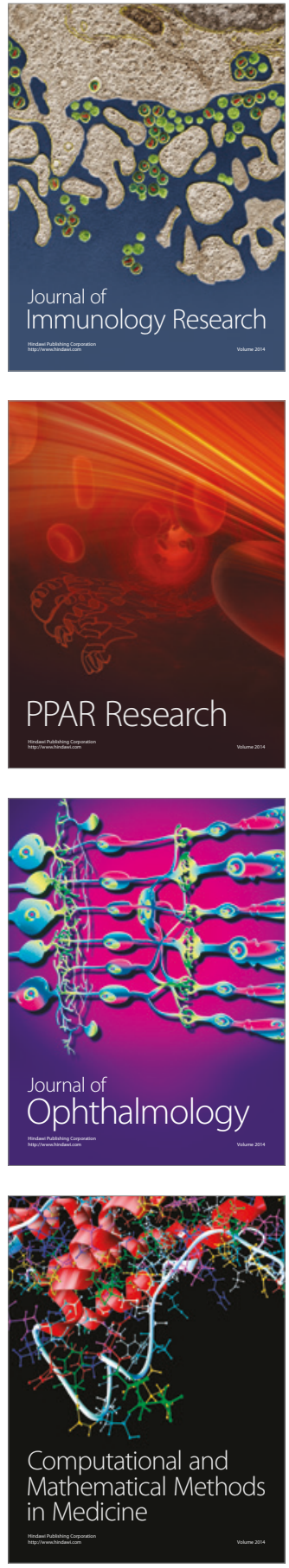

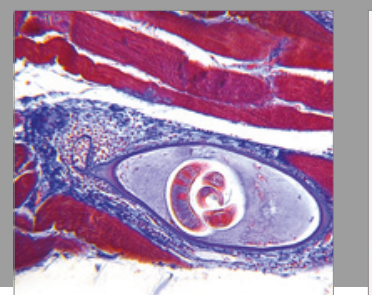

Gastroenterology Research and Practice
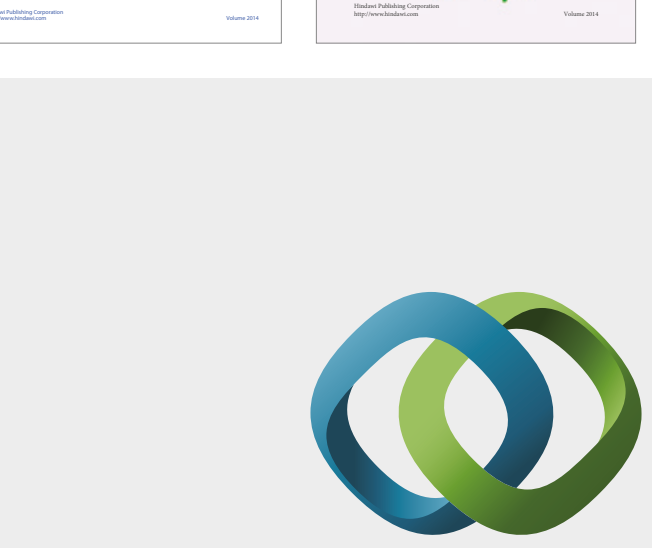

\section{Hindawi}

Submit your manuscripts at

https://www.hindawi.com
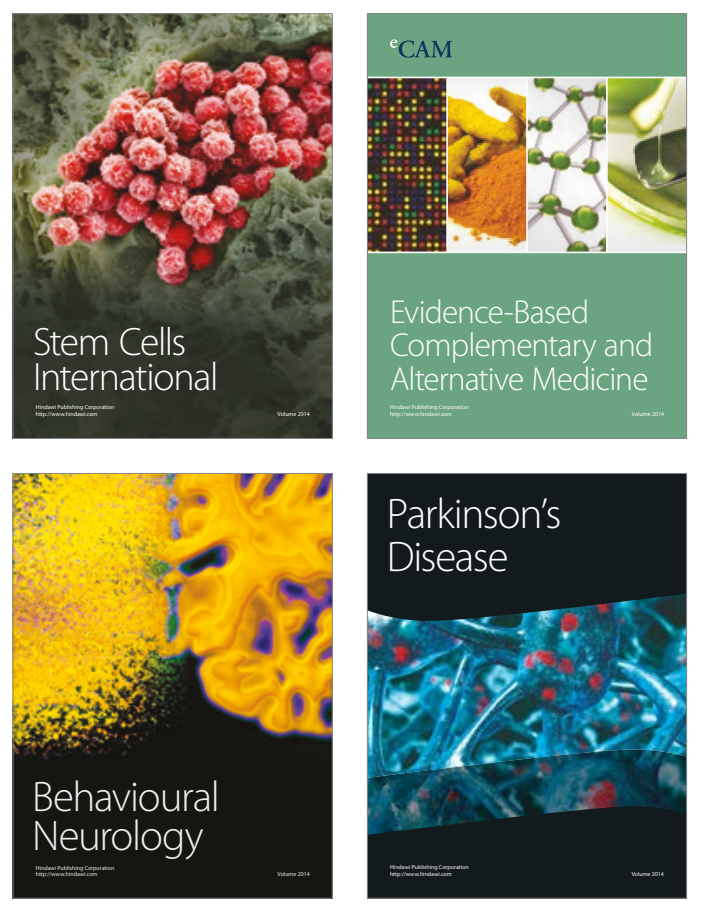
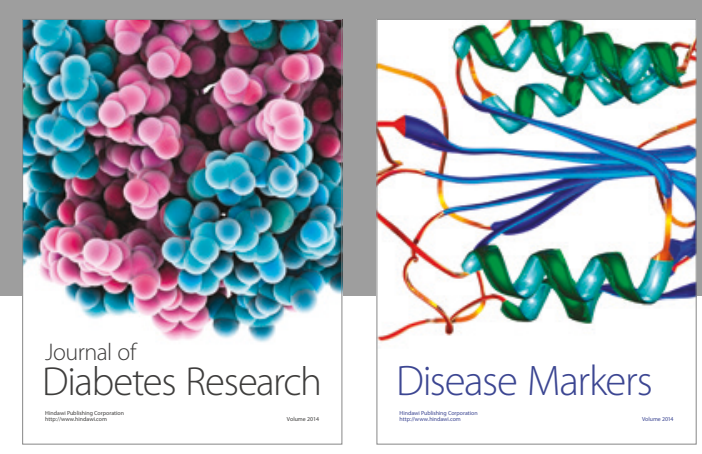

Disease Markers
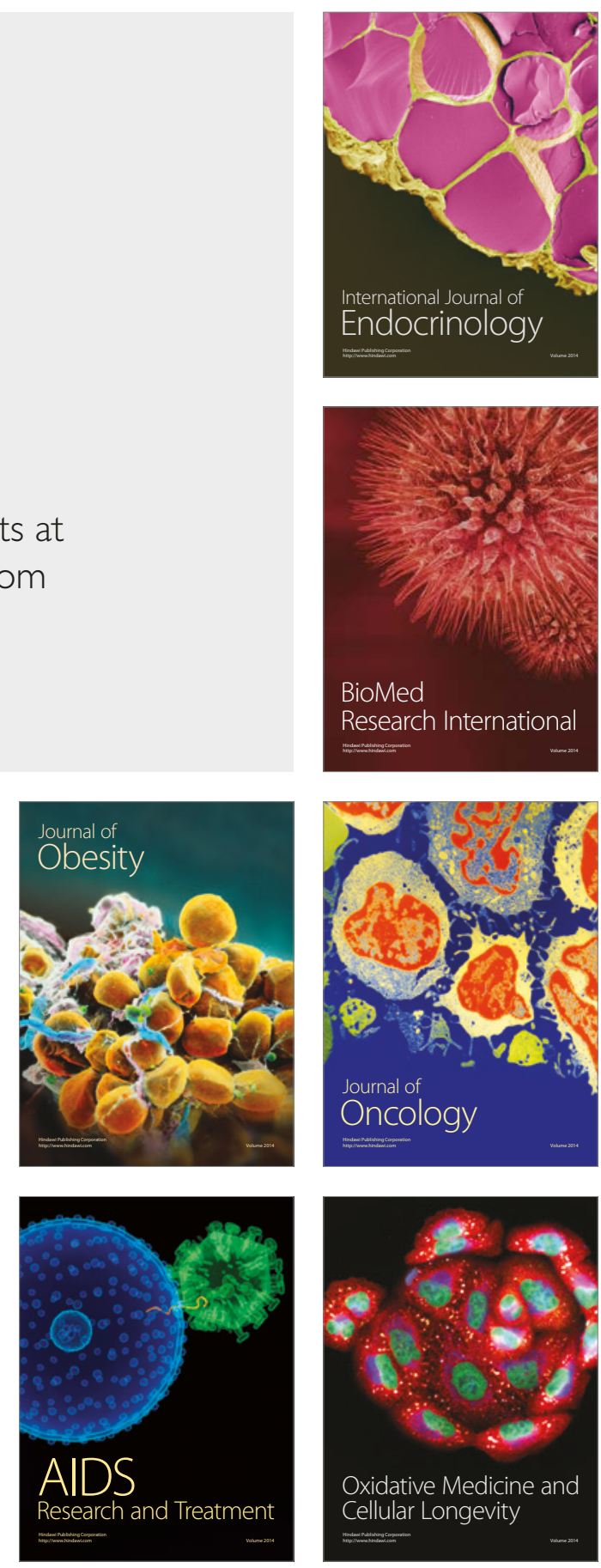